\title{
Madres narcotraficantes: Las motivaciones de ingreso al narcomundo en mujeres internas en el Centro Penitenciario Femenino de Chillán, Chile
}

\author{
Drug-dealings mothers: Motivations on getting into the drug-dealing world \\ of imprisioned women in the Chillan's Female Prison of Chile.
}

Gustavo Riquelme Ortiz* y Omar Barriga**

\begin{abstract}
Resumen
El objetivo de esta investigación es comprender las situaciones y agencias para practicar el narcotráfico relatadas por las internas del Centro Penitenciario de Chillán. Los principales hallazgos son relativos a los beneficios económicos asociados al tráfico de drogas, pero además, a las distintas significaciones otorgadas por las mujeres a este negocio; sobre todo en lo que compete a sus hijos y a la posibilidad de generar relativa autonomía respecto a sus parejas. Además, se describió un tránsito desde un machismo cultural hegemónico, que influye a las mujeres a ingresar al narcotráfico en busca de generar recursos sin desligarse de los roles tradicionalmente femeninos, hasta un machismo cultural delictivo, caracterizado por el estancamiento estructural al que el narcotráfico condena a la mujeres, otorgándole status de mayor riesgo, menores excedentes y menores cuotas de poder.
\end{abstract}

Palabras Clave: género, machismo, tráfico de drogas, metodología cualitativa, cárcel.

\begin{abstract}
The purpose of this research is to comprehend the situations and agencies in play during the practice of dealing drugs described by the female inmates of the Chillán Correctional Center. The principal findings deal with the economic benefits related to drug dealing, but also the diverse meanings that these women ascribe to this activity; primarily, those related to their children and the possibility of gaining relative autonomy from their partners. Furthermore, we describe a transition from a hegemonic cultural machismo, which influences women to enter drug dealing in search of new resources without abandoning their traditional feminine roles, to a delinquent cultural machismo characterized by the structural stagnation to which drug dealing relegates these women, granting them greater risks, fewer profits and even less amounts of power.
\end{abstract}

Keywords: gender, machismo, drug-dealing, qualitative methods, jail.

\footnotetext{
*Sociólogo, gustavoriquelmeortiz@gmail.com

** PhD en Sociología, Profesor Asociado del Departamento de Sociología y Antropología de la Universidad de Concepción, obarriga@udec.cl.
} 


\section{El narcotráfico, consideraciones teóricas y empíricas}

Chillán es una ciudad intermedia ubicada en la provincia de Ñuble, región del Biobío, cuya población es alrededor de 175.000 habitantes. Este centro urbano es una urbe emergente y tradicional, cuyo principal sustento económico es la agricultura y los servicios. En este contexto se ubica el Centro Penitenciario Femenino (CPF) de Chillán, recinto pequeño que al momento de la investigación contaba 85 internas en régimen cerrado y semiabierto. Se caracteriza por ser una cárcel "folclórica" con buenas relaciones entre internas y funcionarias, cuyo espacio está anexado al Centro de Cumplimiento Penitenciario Masculino de la ciudad desde 2010.

Al revisar la literatura sobre el problema, se aprecia que la criminalidad en Latinoamérica se ha configurado como un problema social que ha influenciado a los Gobiernos y Organismos Supranacionales a desarrollar políticas y programas tendientes a solucionar esta situación (Galindo y Catalán, 2007). De acuerdo a la descripción estadística de Gendarmería de Chile (2013), hacia finales de 2013 la Institución atendía una población total de 294.696 reclusos a lo largo del país en los distintos subsistemas carcelarios (Subsistema cerrado, semiabierto, abierto y post-penitenciario), donde las mujeres representan el $11,27 \%$ de la población penal. De ellas, 1755 mujeres están privadas de libertad a raíz del tráfico y consumo de drogas, de acuerdo a las infracciones a la Ley 20.000 y al Artículo 5 de Tráfico llícito de drogas, lo que representa el 37\% del total de las mujeres reclusas, destacando el microtráfico de drogas como la principal causa en el ingreso de mujeres a Recintos Penitenciarios. A diferencia de los hombres cuyo motivo de ingreso más común es el robo con intimidación (Gendarmería de Chile, 2013; Cárdenas y Undurraga, 2014). En las últimas décadas se ha desarrollado un aumento exponencial en el ingreso de mujeres a recintos penitenciarios para cumplir condenas privativas de libertad, superando la tasa de crecimiento de los hombres en el mismo periodo (Gendarmería; 2013); observándose que cada vez más mujeres participan de (y son detenidas por) el tráfico de drogas en Chile.

En general, se ha asociado la criminalidad con el uso y tráfico de drogas ilícitas, donde se pueden distinguir tres hipótesis. La primera asegura que la droga es un factor causal de la delincuencia, pues la necesidad de obtener drogas introduce a los sujetos al mundo delictual con el fin de conseguir recursos para financiar su consumo; la segunda hipótesis plantea que la delincuencia es un factor causal del consumo de drogas al introducir a los sujetos a un mundo donde está presente la droga; sin embargo, la tercera hipótesis es la más respaldada, es decir, no existiría vínculo causal entre estas variables, describiendo una relación espuria, a pesar de la evidencia que afirma que la drogodependencia contribuye a la criminalidad de forma indirecta (Rodríguez, Paíno, Herrero y González, 1997).

Por otro lado, diversos autores (Arriagada y Hopenhayn, 2000; Hopenhayn, 2001; Cooper, 2002; Galindo y Catalán, 2007) plantean que el tráfico de drogas es un problema difícil de suprimir por el carácter lucrativo que ofrece a sus agentes, cuestión complementada con la generación de "una cantidad importante de empleo directo en actividades conexas e indirecto en el lavado de dinero" (Arriagada y Hopenhayn, 2000:17). Siguiendo este argumento se ha planteado que los sujetos participan del 
tráfico de drogas dependiendo de los sacrificios y ganancias potenciales, cuestión modelada por la estructura de preferencia y los valores morales presentados por los sujetos (Galindo y Catalán, 2007); es decir, el tráfico de drogas viene dado por un análisis costo-beneficio en conjunción con el sistema de valores. Cárdenas y Undurraga (2014) han planteado que las mujeres ingresan al narcotráfico en busca de un sustento para sus familias, pues las actividades delictivas aparecen como una vía rápida para conseguir lo que materialmente necesitan, a pesar de las consecuencias como la inseguridad o el riesgo de encarcelamiento. "Es la inmediatez de las necesidades y su satisfacción mediante el dinero rápido (ilegal) lo que ha solido orientar las acciones de estas mujeres hacia el micro-tráfico" (Cárdenas y Undurraga, 2014:294). En un sentido menos centrado en el sujeto, el contexto influye en las conductas delictivas - el tráfico de drogas - donde la participación en estas actividades está influenciada por un historial familiar delictivo - contextual -más que por un análisis personal costo/beneficio (Ordóñez, 2006).

En un sentido económico, Doris Cooper afirma que en la economía informal alternativa ilegal:

surgen oportunidades laborares ilegales asociadas a las clases sociales más bajas del sistema y en consecuencia a la sobrevivencia, entre las que destacan la contracultura del hampa (ladrones), la Mafia del tráfico de drogas, particularmente en pequeña escala, prostitución infanto-juvenil, el trabajo infantil y juvenil, y el Comercio Ambulante (2002:545).

Y sintetiza afirmando que "se trata de la economía de los pobres y extremadamente pobres, constituida por roles que les permiten sobrevivir" (p.548).

En definitiva, todas estas visiones sobre las causas del narcotráfico aparecen como complementarias y conflictivas a la vez. Por un lado la perspectiva de costo-beneficio involucra la evaluación de las posibilidades reales de emprender una ocupación remunerada, reconociendo la marginalización de algunos sujetos del mercado laboral y productivo, donde las posibilidades de ingreso antes mencionadas se ven limitadas, por lo que el narcotráfico se aprecia como una alternativa que permite sobrevivir a una masa de marginados y marginalizados (Cooper, 2002). La tesis que la exclusión del mercado impulsa a ciertos sectores al narcotráfico es apoyada por Arriagada y Hopenhayn, pues "el narcotráfico se constituye fácilmente en una estrategia de supervivencia adoptada por mujeres con jefatura de hogar e incluso por personas de tercera edad de escasos recursos" (2000:18), donde resalta la dimensión contextual de los traficantes por sobre la pura elección racional, es decir, aparecen como más influyentes las condiciones de vida. Se puede identificar la familia y la pareja como los principales agentes socializadores de los modos de vida y del aprendizaje de los oficios ilegales, por lo que el sentido del microtráfico para las mujeres se encuentra estructurado por las propias vivencias en el proceso de socialización en contextos marginales, donde el acceso a dicha formación e información es más inmediato y cotidiano (Cárdenas y Undurraga, 2014). Sin embargo, el sólo hecho de considerar el ingreso al narcotráfico como beneficio no significa que el o los sujetos puedan efectivamente entrar a estas redes, pues como han dicho Silva y Anaya (2004) en un estudio del narcotráfico en Brasil, las redes de tráfico de drogas están compuestas en su 
mayoría por amigos y familiares que tienen vínculos de afecto. Estos sujetos normalmente ocupan puestos importantes dentro de la jerarquía de la red, por lo que se puede establecer una asociación diferencial (en el sentido de Sutherland) entre estos sujetos, pues se van integrando y cohesionando en la medida que son cómplices del narcotráfico. La articulación de estas redes se ven favorecidas, por la práctica de códigos y valores morales y por "las dimensiones tecnológicas que generaron un incremento de la circulación de capitales, información y personas a una escala mundial" (Silva y Anaya, 2004:142).

Tomando estos antecedentes en cuenta, parece precipitado buscar y hablar de "causas" del narcotráfico, como ha planteado Goffman, en cuestiones delictuales como el narcotráfico intervienen una multitud de variables, pues son comportamientos pluriformes y complejos (en Galindo y Catalán, 2007). En tal sentido, parece más adecuado hablar de influencias y motivaciones al tráfico de drogas, como se ha tratado en el estudio recién citado.

El narcotráfico no debe ser entendido tan sólo como una conducta criminal o una actividad económica ilícita, sino como una forma de vida que genera cambios en las condiciones culturales, económicas y sociales de existencia, pues el tráfico de drogas en muchas urbes latinoamericanas genera (o refuerza) una cultura de la ilegalidad basada en la violencia, la cual termina por corroer las normas mínimas de sociabilidad (Arriagada y Hopenhayn, 2000; Silva y Anaya, 2004; Ovalle y Giacomello, 2006). Esta idea es reforzada en el estudio de Silva y Anaya del 2004, donde explican que los habitantes de las favelas, los cuales se ven rodeados de una narcocultura, establecen una división y oposición entre el morro - la favela - y el asfalto - Rio de Janeiro -, donde cada entidad tiene sus propias reglas y códigos de conducta, que aunque tienen elementos comunes, tienen también elementos notoriamente contradictorios. Doris Cooper (2002) también ratifica esta idea, planteando que en la Economía contracultural los marginados y marginadas encuentran un nicho de desarrollo personal que les permite alcanzar prestigio alternativo y reconocimiento social en ese contexto. Sin embargo, estas dos economías - y culturas - no están fracturadas una de la otra, no son dicotómicas, más bien generan un "continuum" (Silva y Anaya, 2004:149) entre los polos. En tal sentido, si bien Cooper habla de una Contracultura delictual (2002), parece más acertado hablar de una subcultura del narcotráfico, en tanto existen convergencias y divergencias en el contenido cultural de ambas, sin plantear necesariamente una nueva alternativa al orden sociocultural. Valores como la solidaridad, amistad y lealtad, entre otros, son apreciados en ambos polos (Ovalle y Giacomello, 2006). Así, el narcotráfico se apodera de espacios que tienen un determinado ethos -entendiéndolo como las actitudes que toma un grupo ante condiciones de existencia determinadas, es decir, como el estilo de vida aprobado- ya existente, propicio para reproducir la estructura del crimen organizado (Silva y Anaya, 2004). Contrario a esta propuesta, Ovalle y Giacomello (2006) han planteado que el narcotráfico genera

una serie de cambios y trasfiguraciones sociales y culturales relacionadas directamente con el establecimiento de nuevas pautas de interacción, cambio en los valores, procesos de legitimación, entre otros. En este sentido, queda claro que el narcotráfico establece pautas definidas de interacción social entre los 
diferentes actores; y es a partir de dichas manifestaciones que (...) plantean la existencia de una cultura del narcotráfico o "narcocultura"” (Ovalle y Giacomello, 2006:300).

De esta manera, sería el narcotráfico quien genera un ethos y ocupa un espacio determinado, modificando las relaciones sociales y las estructuras morales para generar crimen organizado. Ambas posiciones tienen asidero empírico, por lo que se podría considerar que el narcotráfico aporta en la creación de un espacio y una cultura, y a su vez, dicho espacio ocupado debe tener características culturales y sociales relativas al narcotráfico, por lo que hay un diálogo entre el ethos de la comunidad y el ethos del narcotráfico.

El delito del tráfico de drogas se constituye como un ilícito característico de espacios urbanos e industriales que rinde ganancias significativas e involucra diferentes estratos socioeconómicos a nivel mundial (Cooper, 2002), pero sin embargo reviste otras características al interior de los centros penitenciarios. En general, los reclusos -al interior de una cárcel- son sujetos institucionalizados, es decir, sujetos donde la institución carcelaria se ha entrometido forzosamente en su intimidad, controlando todos los aspectos de su vida y su rutina, ejerciendo poder sobre su cuerpo (Ordoñez, 2006). Esta cuestión viene a ratificar la tesis de Foucault ${ }^{1}$ que ve en las prácticas penales una consecuencia de la anatomía política más que de las teorías jurídicas (1975) y que entiende por disciplina "métodos que permiten el control minucioso de las operaciones del cuerpo, que garantizan la sujeción constante de sus fuerzas y les imponen una relación de docilidad-utilidad" (1975:141). De esta forma, el encarcelamiento y disciplinamiento carcelario que habla Foucault genera dos rupturas importantes en la historia de vida de las reclusas (Ordoñez, 2006) -quienes fueron las entrevistadas en este estudio-, la primera es la separación y pérdida de contacto con los hijos que genera un sentimiento de culpa e impotencia, y la segunda ruptura es la infantilización de la interna, es decir, la sumisión a un régimen tutelar que imposibilita a las reclusas tomar decisiones adultas, tener autonomía y libertad, degradándola a un status infantil, cuestiones favorecidas por la existencia de una vigilancia invisible en el sentido foucaultiano. Sin embargo, también hay relaciones de poder entre reclusas que, en el caso de las narcotraficantes, suelen ser utilizadas como asesoras domésticas de las Ladronas - dependiendo del status de la traficante - y marginadas del resto de las reclusas (Cooper, 2002).

Con todos estos antecedentes, se hace necesario analizar la criminalidad y el narcotráfico en relación con las mujeres, los sujetos estudiados en esta investigación. Cooper (2001) distingue dos nichos etiológicos fundamentales en la delincuencia femenina, se habla de la pobreza y la extrema pobreza y el machismo cultural al interior (y exterior) de la esfera del narcomundo (Cooper, 2001). Sin embargo, aunque en el libro de Cooper aparecen al menos conceptualmente separados, en términos reales son dos

\footnotetext{
${ }^{1}$ Aunque el concepto de Foucault es relativo a la prisión, también puede ser extendido a la narcocultura, pues como se dijo, está basada en el uso de violencia, el cual justamente busca imponer una relación de poder y docilidad con los sujetos de las redes de narcotráfico. Sin embargo, el uso disciplinario de la violencia también se conjuga con compromisos mutuos de reciprocidad (Silva y Anaya, 2004)
} 
caras de una misma moneda. Diversos autores (Cánovas, 2001; Cooper, 2001; Kalinsky, 2003a, 2003b; Carrillo, 2012) sostienen que ante la inseguridad y dependencia económica de la mujer en una sociedad claramente patriarcal, el narcotráfico representa una alternativa laboral atractiva para esa masa de mujeres marginadas que, conscientes de los riesgos que implica el narcotráfico, los menosprecian ante los beneficios económicos. De hecho, se caracteriza el perfil de las traficantes de drogas como madres solteras que son fuente de ingreso para su familia o como ancianas solas, sin cónyuge y de escasos recursos (Cooper, 2001). Las mujeres, además, representan una ventaja para la estructura del tráfico de drogas, pues se cree que despiertan menos sospechas ante las autoridades, al punto que en momentos de crisis y desempleo, a las mujeres se les ofrece más oportunidades laborales ilegales que a los hombres (Del Olmo, 1992). Esta imagen de la mujer como un sujeto-objeto que presenta menos riesgos también se demuestra en otras investigaciones. Por ejemplo, Héau (2007) muestra la posición subordinada de la mujer ante la figura teatralizada del hombre en los narco-corridos mexicanos, donde el varón es un sujeto valiente, bravío y violento frente a una mujerobjeto en términos sexuales y amorosos. Esta imagen subordinada se conjuga con la de malas madres para aquellas traficantes y consumidoras de drogas, pues introducen a sus hijos a vivir en medio de un mundo caracterizado por la ilegalidad. Al respecto, Cárdenas y Undurraga (2014) han planteado que las mujeres involucradas en el tráfico y microtráfico de drogas cuestionan el orden de género y la noción de trabajo. Argumentan que esto se debe, en primera instancia, al no cumplir las expectativas sociales de género respecto a sus roles domésticos y reproductivos, especialmente bajo la etiqueta de "malas madres"; y en segunda instancia al evidenciar la segregación laboral que sitúa a las mujeres en status de menor poder y subordinación, tanto en el mercado laboral legal como ilegal.

Actualmente se sabe que las mujeres que trabajan en el narcotráfico lo hacen al menudeo, ventas al por menor, como una suerte de economía de subsistencia, ubicándose en los últimos eslabones de la larga cadena de intermediarios de la droga (Cooper, 2001; Kalinsky, 2003a), pues el rol de la mujer es secundario y aunque algunas logren integrar espacios jerárquicos en la estructura del narcotráfico, es por un reflejo de los cambios en el mercado laboral legal donde, a pesar del aumento de la participación femenina en la esfera del trabajo, éstas ocupan puestos subordinados, no estratégicos y de alto riesgo (Carrillo, 2012).

\section{Enfoque metodológico}

El objeto de estudio son los factores que influyeron a las mujeres de la cárcel femenina de Chillán para practicar el narcotráfico. Por una cuestión estratégica, el campo de estudio para la temática de investigación es la cárcel de Chillán, pues en ella se cuenta con la seguridad necesaria para no exponer al investigador a situaciones peligrosas.

La población estudiada son las mujeres internas por narcotráfico en la cárcel de Chillán, población que alcanza un total de 27 mujeres cumpliendo condena por causas relacionadas al tráfico de drogas, bajo los delitos de infracción a la Ley 20.000 de control de microtráfico de drogas. La información oficial para determinar los criterios de 
muestreo fueron limitadas (edad, tipo de infracción, tipo de sustancia y condena); sin embargo las informantes claves desarrollaron un rol trascendental para caracterizar la población y encontrar variedad en la muestra. Las Informantes fueron mujeres que tuvieron buenas relaciones con las internas, además de un conocimiento acabado de la situación de cada una de ellas y con los contactos necesarios para conseguir entrevistas y facilitar los procesos administrativos para entrar al Centro Penitenciario. Las informantes claves fueron una voluntaria de la Pastoral Penitenciaria y una de las trabajadoras sociales del CPF de Chillán.

Para la selección de entrevistadas se utilizaron algunos criterios considerados importantes en investigaciones similares, como los hijos (Ordoñez, 2006), el consumo de drogas y la experiencia laboral (SENDA, 2010), junto a otros criterios tendientes a encontrar variedad en la muestra seleccionada, los que fueron controlados a través de las mismas entrevistas y de las informantes claves, pues muchos de ellos no podían ser controlados de otra manera por falta de información disponible. De esta forma, los criterios utilizados fueron: Etapa en la vida de la mujer, hijos, tipo de droga que traficaba, tipo de tráfico, consumo de drogas, antecedentes familiares de tráfico y/o consumo de drogas, educación, nivel socioeconómico y reincidencia.

Las entrevistas fueron voluntarias siguiendo los criterios anteriores. Por cuestiones estratégicas, se comenzó entrevistando a la interna de mayor edad, por ser una mujer querida y respetada por las internas, considerada la "madre" en el encierro, facilitando el trabajo de campo al socializar la experiencia de "ser entrevistada". Es importante señalar que las entrevistas se realizaron en la escuela de la penitenciaria sin supervisión de gendarmería. De esta forma, 10 mujeres fueron seleccionadas de acuerdo a los criterios anteriores, de las cuales dos negaron su participación en las entrevistas y sólo se logró reemplazar a una de ellas bajo los mismos criterios, por lo que se constituyó una muestra de 9 mujeres entrevistadas en una o dos sesiones, generando alrededor de once horas de grabación durante las primeras dos semanas de diciembre de 2012.

Debido a la imposibilidad de continuas visitas a las internas de la cárcel y con el objetivo de conocer los relatos y experiencias que tienen dichas mujeres, se utilizó como técnica de recolección de datos la entrevista semi-estructurada, desarrollada en base a preguntas abiertas que guiaron la conversación con las entrevistadas.

Las entrevistas, luego de ser transcritas, fueron analizadas según la técnica de análisis de contenido, pues es un "técnica de investigación destinada a formular, a partir de ciertos datos, inferencias reproducibles y válidas que puedan aplicarse a su contexto" (Krippendorf, 1990:28). La ventaja que plantea esta técnica es que permite un análisis lingüístico de las estructuras formales del lenguaje y comparar los sentidos de los discursos para identificar componentes y experiencias revelados a través del lenguaje (Blanchet y Gottman, 1992 en Baeza, 2002). De esta forma se permite, en base a unidades de análisis (frases y oraciones), formar síntesis temáticas y sub-temáticas (Flick, 2007; Baeza, 2002) ad-hoc a la entrevista semi-estructurada. En tal sentido, se utilizaron los criterios de categorización propuestos por Ruiz Olabuénaga (2007), construyéndose un sistema de codificación abierta en un comienzo para progresivamente delimitar las categorías hasta finalizar con un sistema de codificación 
cerrado.

Los temas, subtemas y categorías generadas a partir de los datos y desde el marco referencial (Ruiz Olabuénaga, 2007; Baeza, 2002) fueron procesados con el programa Atlas.ti, para manejar de forma más eficiente las entrevistas.

\section{Análisis y principales resultados}

Para contextualizar el análisis, se debe tener en cuenta que las entrevistadas son de distintas ciudades, pero fueron detenidas y formalizadas en Chillán, ciudad intermedia que no se caracteriza por rasgos cosmopolitas; más bien es una ciudad emergente y tradicional. En tal sentido, el Centro Penitenciario Femenino tiene características distintas como manifestó la informante clave "Esta es una cárcel bastante... em... folclórica como puedes ver" (I.C.1 $)^{2}$, lo que ha influenciado en evaluar la permanencia en la cárcel por sobre el traslado a la ciudad de origen "pero tampoco me quiero ir porque acá hay buenos beneficios. Cárcel más chica, allá es grande [Santiago], hubiese ido mal allá" (C-E6, 25). Tomando esto en cuenta, se pueden establecer algunas relaciones basadas en los datos, las cuales serán expuestas a continuación.

La principal motivación para ingresar al mundo del narcotráfico fueron los beneficios económicos percibidos, pues en la mayoría de los casos la venta de drogas se hace en el mismo sector de residencia, por lo que no implica movilidad continua por la ciudad. Sin embargo, afirmar lo anterior no es nada nuevo, es sólo la confirmación de hipótesis que ya han sido validadas: que el narcotráfico es un negocio altamente lucrativo (Córdova, 2007; Galindo y Catalán, 2007; Ovalle y Giacomello, 2006; Silva de Sousa y Anaya, 2004; Cooper, 2002; Arriagada y Hopenhayn, 2000), aunque no a todo nivel, sino principalmente para traficantes con mayores cuotas de poder. A pesar de lo anterior, se puede realizar un análisis más exhaustivo de esta categoría que devela una densa red de relaciones, sobre todo cuando se analiza el género y los hijos. A saber, los beneficios económicos de la venta de drogas actúan como motivación y como consecuencia del ingreso al mundo del narcotráfico. La distinción en la forma en que actúan los beneficios económicos (motivación o consecuencia), es sólo una distinción analítica, pues en el campo actúan conjuntamente, con mayor o menor importancia cada una, de acuerdo a los datos obtenidos. Cuando actúan como motivación es porque las mujeres ya conocen el mundo del narco de antemano, ya sea por el consumo de sustancias ilícitas, porque en el lugar donde vive es conocido cómo funciona dicho mundo, es decir, es parte de su contexto diario de desenvolvimiento, y de cierta forma, ha sido naturalizado: "En la población donde vivo yo, casi toda la gente hace eso, casi todos vendían po. No era drama" (A-E2, 52). El conocimiento sobre las drogas, entonces, proviene del consumo, de la presencia de droga en el lugar de residencia y/o de la relación que sostengan familiares con el mundo de la droga (es decir, que los familiares consuman o sean

\footnotetext{
${ }^{2}$ Este tipo de paréntesis posterior a las citas textuales de las entrevistas corresponde al rotulado de las entrevistadas para no señalar su nombre. Para este caso, corresponde a la Informante Clave 1 (I.C.1). El resto de los rotulados corresponde a la inicial del nombre de la entrevistadas, luego el número de su entrevista y su edad, por ejemplo "(C-E6, 25)".
} 
traficantes), por lo que el conocimiento previo que se tenga sobre el mundo de la droga es una puerta de entrada al narcotráfico, pues las mujeres nunca entran sin saber los riesgos, siempre hay una información que media la decisión de entrada al negocio. Como relata una entrevistada:

"Ya, me dieron la mano pa comprar coca y ya po, me puse a vender coca sin saber. iO sea! Una a sabiendas igual... si yo no voy a decir que a mí me pusieron una pistola en la boca y que tení que vender, no. Pero a mí me iba a bien y itodos vendían po!" (S-E1, 63).

El conocimiento sobre las drogas permite a las mujeres realizar una evaluación previa antes de ingresar al mundo del narcotráfico, donde se comprenden los riesgos pero se desestiman, primero, por la importancia de las motivaciones, y luego, por el cumplimiento de las expectativas económicas y las consecuencias positivas asociadas, pues se sabe que en cualquier momento "iba a llegar la mano que aprieta" (Y-E5, 32). Sin embargo, para el caso de las reincidentes, la mano que aprieta, es decir, todo el proceso judicial posterior al allanamiento o la detención por tráfico de drogas, es sólo un costo que están dispuestas a pagar por recibir los beneficios asociados al narcotráfico, "... pa qué te voy a mentirte que no voy a seguir viviendo del tráfico... seria mentirosa. Esto que he estado aquí igual me ha servido para pensar hartas cosas, pa recapacitar... pero no sé po, igual me gusta" (J-E7, 22).

Además de los beneficios económicos, existen al menos tres agencias que actúan como motivación para el ingreso y permanencia en el mundo del narco. Primero están los hijos, donde se hace una evaluación personal que incluye la forma en que las mujeres vivieron su infancia y como quieren que sus hijos vivan la suya, donde siempre hay mayores aspiraciones, no tan solo económicas, sino también educacionales y relativas al nivel de vida, como relata una de las entrevistadas:

Si po. Si igual cuando yo estudiaba mi papi era de los que llegaba fin de año, pedíamos ropa nosotros y él decía "ya, les compro ropa pa navidad o les pago las cuotas del curso", entonces nos daba a elegir, era una sola cosa, entonces yo no quería eso pa mis hijos. Ojalá comprarle ropa todos los meses, pagarle en el colegio para que vaya a una fiesta a fin de año. Yo lo hago. Entonces no quiero que mis hijos pasen por eso, ¿cachai?" (A-E3, 29).

También el deseo de tener la casa propia es una motivación para el ingreso al narcotráfico. Todas las entrevistadas manifestaron ese anhelo, que con los excedentes de la venta de drogas se trasforma en meta, y para algunas, en realidad. La casa propia entrega independencia, status y estabilidad en la vida, transformándose en un punto de inflexión de la vida de las mujeres, permitiéndoles proyectarse en la vida de manera independiente, rompiendo la lógica machista que domina el narcotráfico: “...yo me lo pasaba en la casa, porque igual no me dejaba trabajar, no me dejaba tener mis cosas, nada" (Y-E5, 32). En tal sentido, ante la dependencia económica de las mujeres para alcanzar sus deseos, el narcotráfico aparece como una forma de generar dinero sin romper con la lógica tradicional de los roles de la mujer, pues les permite estar en casa, seguir criando a los hijos y esperar al marido cuando este llegue del trabajo. La lógica 
machista, sin embargo, no es solamente impuesta; sino reproducida por las mismas mujeres, ya que abalan dicha situación y sólo se dedican a "ayudar" al marido cuando el negocio del narcotráfico es una empresa familiar; y lo hacen a escondidas de él cuando es un emprendimiento personal, pues es mal visto que una mujer sea vendedora de droga.

Así, el ingreso al narcotráfico permite trasformar en realidad el sueño de la casa propia, sobretodo en contextos de vulnerabilidad donde vivían como allegadas, arrendatarias o en tomas de terreno. La casa propia es una agencia que actúa como motivación para el ingreso al mundo del narco, pero sin romper con la lógica machista que establece los roles tradicionales de género a las mujeres:

Él igual trabajaba en las dos cuestiones [obrero y traficante] pero no me daba, no me daba y yo quería igual vestirme de otra forma, tener más cosas... no sé po, yo dije este va a ser mi hombre y con él me voy a quedar el resto de mi vida. Yo así pensaba, pensé que iba a tener mi casa, mis cosas... güeá que nunca logré porque siempre tuve mi pieza no más, la pura pieza. Me entendí. Nada más que eso (J-E7, 22).

Por otro lado, los beneficios económicos del narcotráfico también actúan como consecuencia, de una manera obvia, como se dijo anteriormente. Sin embargo, estos beneficios no son significados de la misma forma por las entrevistadas, pues se distingue una diferenciación, dependiendo del lugar que ocupan en la jerarquía del mundo del narco, pues para quienes sólo actuaron como palo blanco, las ganancias económicas sólo servían para darse $v$ velta $^{3}$, es decir, para satisfacer necesidades básicas, cubrir deudas o mejorar la calidad de vida, como relata una entrevistada "... porque el tráfico pa lo que me dió fue pa darme vuelta, pa comer bien, pa tener exquisiteces, pero yo no te puedo decirte que con el tráfico yo me compré un tele, un refri, no." (M-E5, 32). Por otro lado, las pica's a ñoña, es decir, las mujeres que alcanzaron alto status en el narcotráfico, lo hicieron por ser pareja de varones con altos status -una mujer difícilmente podrá alcanzar altos espacios de poder sin ser cobijada por un varón- y describieron otra forma de valorar el dinero, pues al superar las expectativas de ganancias no desarrollaron ánimos de acumulación, por el contrario, comienzan a repartir los excedentes entre familiares y vecinos, vendiéndoles a precio de costo y buscando nuevas formas de encontrar emoción delinquiendo, como el robo hormiga o la mecha ${ }^{4}$. Dentro de la muestra, la única mujer que alcanzó un status mayor por ser pareja de un ñoño ${ }^{5}$, relata:

\footnotetext{
${ }^{3}$ La lógica de darse vuelta es la siguiente. Cuando las mujeres utilizan el narcotráfico como segundo ingreso, no como ingreso principal, el dinero recaudado es destinado a dos objetivos: cubrir gastos que antes no podían como deudas, mejorar la alimentación, tapizarse (vestir ropa de marca), etc. Y también a comprar nuevamente la misma cantidadde droga para comercializar.Esto último resulta interesante, pues sólo los palos blancos no desarrollan el afán de reinvertir capital (de hecho, ni siquiera utilizan la palabra capital), cuestión que sí hacen los y las narcotraficantes que venden o trasportan drogas al por mayor, quienes incluso utilizan jerga económica como capital, capitalizar, invertir, reinvertir, riesgos de inversión, etc.; además de términos provenientes del coa como darse vuelta.

${ }^{4}$ Robo de artefactos tecnológicos, ropa y accesorios al interior de multitiendas.

${ }^{5}$ Los ñoños son los narcotraficantes conocido y respetados, que no solo vende drogas al por mayor; sino también tiene personas trabajando para él como guardias, empaquetadores, trasportadores, etc., alcanzando ciertas
} 
Por ejemplo, ya, yo siempre tenía dos palos [blancos], en uno tenía más, tenía todo el ballaco, todos los gramos, y en otro manejaba 50 gramos en la casa y ese poco se lo pasaba siempre a la machucá, entonces de repente pa' no andar todo el día vendiendo, le decía después ya, cuando no tenía pa' qué ver tanta plata, hacia como sesenta pitos y vendía esos sesenta y me entraba. ¡Era! (...) me empecé a aburrir y a mí me gustaba la mecha a mí, me pitiaba los aros en Falabella, ropa, poleras, zapatillas, botas, todas esas cuestiones pa mí, porque después ya no me interesaba estar todo el día traficando, ¿̇cachai? (J-E7, 22).

Los beneficios económicos, al ser consecuencia del narcotráfico, están asociados a beneficios emocionales de dos tipos: (a) con ellas mismas, pues la generación de dinero les demuestra que son capaces de ser autónomas y no depender de nadie, les aumenta la autoestima y la confianza y (b) la posibilidad de darle lujos a sus hijos que ellas no tuvieron en su infancia, fruto de las expectativas que tienen para los suyos.

Por supuesto, las entrevistadas también relatan consecuencias negativas asociadas al tráfico de drogas. La estadía en la cárcel es la principal consecuencia negativa, tanto para primerizas como reincidentes, aunque las últimas tienen una valoración menos negativa que las primeras, pues saben que haciendo conducta ${ }^{6}$ pueden acortar su pena. Estar en la cárcel para las internas significa dos cuestiones fundamentales, (a) perder calle que se refiere a perder la libertad de transitar por la ciudad, pero también perder la autonomía al ser constantemente vigiladas:

Aquí no se sufre nada de pan, porque hay demás comida, pero el hecho de estar encerrada, a las 5 de la tarde estar en dormitorio, a las 8 tomando desayuno, esas cosas uno en su casa... toma cuando quiere, se levanta a la hora que quiere. En el dormitorio hay 3-4 teles, como 5 radios y uno no sabe qué pasa y eso a uno hace que se arrepiente (E-E8, 47)

Por otro lado, también significa (b) perder relación con las familias, principalmente los hijos, donde la culpa se relaciona con el tiempo, ya que la infancia de los hijos no volverá y es un tiempo que no se puede recuperar con nada; además del contacto físico limitado que tienen con ellos, lo que deriva en desapego o en tristeza de parte de los mismo niños y niñas. El testimonio más significativo al respecto es el de $\mathrm{C} 25$, santiaguina, quien relata que su hijo comenzó a decirle tía y a reconocer como madre a su abuela, producto del poco contacto físico que mantenían:

No, no, no... yo tuve que aclarárselo que era la mamá (dice con vergüenza) ¿Y TE DOLIÓ?

Mucho (toma aire), mucho po. Más encima yo llevaba como un año acá, como que se había olvidao de mí (C-E4, 25).

cuotas de poder. Del mismo modo, ser pica's a ñoña es un intento por ser ñoña y sólo eso, pues no podrán seguir escalando en la jerarquía al ser mujer.

${ }^{6}$ Cumplir con ciertas condiciones para rebajar la pena como asistir a cursos de perfeccionamiento laboral, no causar problemas, buena convivencia, etc 
A pesar de ello, y para subsanar la lejanía con sus seres queridos, las mujeres mantienen plásticos escondidos al interior de la cárcel, es decir, teléfonos celulares para permanecer en contacto con sus familias al exterior de la cárcel. Situación que es conocida por gendarmería, pero es parte de una cierta negociación de las normas para mantener calmadas a las internas, pues, como se dijo ser astuta está permitido, por lo que existen espacios de libertad donde las internas pueden romper las normas, pero de manera menos evidente.

Las internas también relatan consecuencias morales de la venta de droga, sin embargo de maneras diferenciadas según el tipo de drogas y la etapa de sus vidas, estableciéndose un vínculo con el conocimiento sobre las drogas, ya sea previo al ingreso al narcotráfico o desarrollado durante el ejercicio de éste. En tal sentido, las vendedoras de marihuana no sienten culpabilidad, pues existe una valoración para cada droga traficada, a saber, la marihuana no es vista como una sustancia mala, pues sus consecuencias no son devastadoras y sus consumidores son de toda índole, desde vecinos hasta empresarios y universitarios. Una de las internas no consumidoras relata sobre su hija:

El pito no me complicaba porque se fumaba un pito y en la taaaaarde se fumaba otro y era, pero la pasta base... a lo más las ollas pasaban susto...pero ya con la pasta no, no comía, no dormía, no le importaba nada, podía estar dos tres días con la misma ropa y no se complicaba (E-E8, 47).

Del mismo modo, la pasta base es una droga perversa, mata-choros ${ }^{7}$, pues los consumidores son los mismos vecinos, jóvenes que en muchos casos comienzan a vender su ropa y parte de los artefactos de sus hogares para conseguir el dinero para el vicio, afectando directamente a sus vecinos, a gente como ellas. Respecto al comportamiento de los consumidores de pasta base, A52 dice:

...si salió de un buzo de marca, un buzo bonito y por ahí llegó con un pantalón rasca, una chalequita que se la lleva el señor... ¿ ¿dónde está la ropa? ...ila cambió por vicio! iiY esas miradas!! Esas miradas como... así como... como andan los looocos, una mirada como asustada (A-E2, 52).

Por otro lado, la cocaína es una droga de elite, el daño que podría provocar sobre las personas es sólo sobre personas con dinero, lejanas a su realidad, pues los pobres no pueden comprar cocaína. De esta forma, la culpa o las consecuencias morales son más fuertes en las traficantes de pasta base, y sobre todo, hacia las traficantes que tienen más familia (hijos y nietos), pues cuando se les pregunta por la evaluación del periodo en que se dedicaban al narcotráfico, reflejaban en sus clientes a su propia familia. "Entonces yo por eso me he arrepentido y no quiero hacerlo más, porque yo no quiero que el día menos pensado vea a un muchacho que yo le he vendido intoxicado, en silla de rueda, yo culpable me voy a sentir" (S-E1, 63), relata una traficante de pasta base no consumidora de 63 años.

\footnotetext{
${ }^{7}$ Referido a que los consumidores de pasta base son ladrones o choros de esquina (Cooper, 2002) que una vez adictos dejan sus actividades legales e ilegales, se mueren, como relatan las internas
} 
Las consecuencias anteriormente desarrolladas fueron relatadas por las entrevistadas cuando se conversaba sobre el presente, es decir, sus apreciaciones eran desde la cárcel hacia la dinámica del narcotráfico; sin embargo, una consecuencia percibida por ellas durante el ejercicio de la venta de drogas es dormir a saltitos, es decir, perder la tranquilidad al interior del hogar, ya que ellas saben que están desarrollando una actividad ilícita -como se dijo anteriormente, existe un conocimiento de la actividad, de los beneficios y los costos-, desarrollando conductas de prevención para pasar piola, es decir, para que sean conocidas en el entorno inmediato y por los consumidores como vendedoras de drogas, pero desconocidas en las fronteras de sus poblaciones, pues representa un peligro al ser identificadas por las autoridades:

Siempre tuve miedo, nunca dormí tranquila, siempre dormía a saltos, por el miedo de que vinieran a reventarme [allanarme] en la noche, pero yo no te vendía en la noche, te vendía durante el día no más, en la noche me estaba en mi casa, (...) yo hacía como que iba a comprar y me descargaba en la misma calle y yo en la mañanita después tempranito iba a dejar a mi hijo a la escuela y rescataba mis weas; nunca menos mal la perdí (Y-E5, 32).

\section{Reflexiones finales}

A modo de conclusión, y en vista de los hallazgos y propuestas teóricas realizadas por distintos autores, se puede señalar que las motivaciones para ingresar al narcotráfico de las mujeres recluidas en el Centro Penitenciario Femenino de Chillán son variadas y actúan conjuntamente, describiendo las mismas características señaladas por muchos los autores referidos, aunque con relativas particularidades. Estas motivaciones, aunque íntimamente relacionadas, pueden separarse analíticamente de la siguiente forma. Por un lado existe una motivación de índole contextual, específicamente, el conocimiento sobre el mundo del narcotráfico asociado a consecuencias positivas -que más tarde se desarrollarán- por sobre las negativas. Este conocimiento se debe entender como una compleja red de relaciones y flujos de información que se encuentran y circulan entre los habitantes de un sector específico -barrio, población, ciudad- y sobre los consumidores de drogas caracterizados en su nivel socioeconómico pues, como ha dicho Hopenhayn (2001), las drogas también llegan diferenciadas a las clases sociales, drogas finas para barrios exitosos y veneno para barrios en crisis. Las mujeres comienzan a vender drogas motivadas por las expectativas de ganancia que pueden o no corresponderse una vez integradas en el narcotráfico y que en general son permeadas por el sistema de valores y la significación de cada droga traficada, por lo que se puede apoyar y complementar la tesis que la entrada al narcotráfico está dada por una evaluación costo-beneficio en conjunción con un sistema da valores (Arriagada y Hopenhayn, 2000; Galindo y Catalán, 2007) propios de los actores, por un lado, y códigos éticos delictuales, por otro; y no necesariamente por un historial familiar (Ordoñez, 2006). Esto último, sin embargo, debe ser especificado, pues sí afecta en el ingreso al narcotráfico los lazos afectivos de las mujeres con otros actores, familiares o no, involucrados en actividades delictivas (Carrillo, 2012).

Otra gran motivación relatada por las entrevistadas, y que guarda relación con la 
literatura especializada, es el efecto de dependencia producido por el machismo cultural sobre las mujeres marginadas, pues al ser económicamente dependiente de sus parejas, el tráfico de drogas ofrece la posibilidad de generar ingresos sin dejar de lado los roles tradicionalmente femeninos. Esta tesis no es nueva, es apoyada por variados autores (Cooper, 2001; Kalinsky, 2003a, 2003b; Ovalle y Giacomello, 2006; Carrillo, 2012; Cárdenas y Undurraga, 2014), pero se puede complementar al analizar la doble influencia del machismo cultural sobre las mujeres narcotraficantes, pues por un lado es un factor de ingreso -como se dijo anteriormente- y por otro es una sentencia de estancamiento estructural, porque no pueden alcanzar grandes cuotas de poder en la jerarquía del narcotráfico, integrando eslabones menores en el tráfico de drogas como palos blancos o vendedoras al menudeo (Cooper, 2001; Kalinsky, 2003b; Ovalle y Giacomello, 2006; Carrillo, 2012) esto les significa, en definitiva, un ingreso menor al de los hombres, desarrollándose una suerte de economía narcotraficante de subsistencia donde la mujer transita del machismo cultural hegemónico al machismo delictual, siendo la única excepción las mujeres pareja de varones de alto status en la jerarquía del narcotráfico. Resulta especialmente gráfico el término "pica's a ñoñas" (J-E7, 22) que utilizó una de las entrevistadas para figurar esta idea de que las mujeres, por su género, no pueden ser-ñoñas; sino únicamente ser picadas-a-ñoñas, es decir, querer serlo, sin serlo.

Los beneficios económicos del narcotráfico ya son conocidos (Córdova, 2007; Galindo y Catalán, 2007; Ovalle y Giacomello, 2006; Silva de Sousa y Anaya, 2004; Cooper, 2002; Arriagada y Hopenhayn, 2000). En el caso estudiado, no actúan como estrategia única de supervivencia, más bien como complementos de actividades legales en las mujeres que son parte de la base de la jerarquía dentro del mundo del narco, ya sea como actividades económicas que apoyan el aporte del hombre al hogar - mediado por el machismo que rodea este mundo - o las pensiones de vejez. Sin embargo, esta situación es distinta para las pica's a ñoñas, pues en ese punto el tráfico es el sustento de vida, no es el complemento de otras ocupaciones, por el contrario; si se realizan actividades son vistas como entretención y no como forma de ganarse la vida, por ejemplo, siendo peluqueras ocasionales para vecinas y amigas sin recibir pago de por medio.

Respecto a los conocimientos antes mencionados, estos vienen asociados a valores que son socialmente compartidos. Cooper (2001) escribe quince valores para el mundo del hampa, pero en el caso de la presente investigación no encontraron sustento. Sin embargo, su modelo teórico enriquece la posibilidad de afirmar que efectivamente existen valores y códigos de conducta en la subcultura del narcotráfico, donde destacan los valores de la responsabilidad ante los compromisos hechos, ser fuerte de mente, es decir, no dejarse amedrentar y estar preparado para los avatares de la vida delictual o, como se maneja en el coa, no ser perkin ${ }^{8}$ de nadie. Este valor está muy asociado al respeto, más que hacia las autoridades, hacerse respetar en los contextos delictuales demostrando la choreza ${ }^{9}$ y ser de una línea, es decir, no torcer la conducta regular que los caracteriza, lo que se dice se cumple, implica además de ser choro, ser correcto.

\footnotetext{
${ }^{8}$ El perkin es un sujeto sometido, casi un sirviente de otro actor que tiene influencia o mayor cuota de poder en un sistema determinado.

${ }^{9}$ En el coa, la choreza es la cualidad de ser agresivo, matón, no-sumiso, etc.
} 
Para terminar, se está en propiedad de afirmar y corroborar la existencia de conocimientos, valores, conductas y cosmovisiones asociadas al narcotráfico, pero sin establecer la existencia de una narcocultura; sino más bien una cultura de la ilegalidad que rebasa la especificidad del narcotráfico, coincidiendo con lo dicho por Cooper "intentamos seriamente con ahínco encontrar en las mujeres condenadas chilenas de clase baja algún indicio de contracultura mafiosa, y sinceramente, nos fue imposible" (2001:343), ratificándose la hipótesis que plantean Silva y Anaya (2004) de la existencia de una continuación entre la cultura hegemónica y la delictual. Los mismos autores plantean que las redes del narcotráfico se caracterizan por estar compuestas por grupos primarios, que es corroborado por los hallazgos de esta investigación, pero dista del carácter positivo que tiene la tecnología al interior del mundo del narcotráfico de acuerdo a los mismos. En el caso de una ciudad intermedia como Chillán, las mujeres prefieren la vinculación cara a cara, pues los aparatos tecnológicos son fácilmente intervenidos por la policía. Este rasgo del narcotráfico puede ser influenciado por el pensamiento provinciano de la ciudad, porque en general se desestima la utilización de tecnologías para la comunicación entre traficantes, materializada en el miedo a los cubos (celulares), valoración que cambia una vez interna en la cárcel, ya que al interior, cualquier medio de comunicación tecnológico es valorado y utilizado para informarse de lo que ocurre al exterior de la cárcel, sobre todo para la comunicación con los hijos. Esto supone un cambio o una ruptura importante en el curso de la vida de las internas (Foucault, 1975), destacando las dos consecuencias encontradas por Ordoñez (2006) y que se reafirman en esta investigación, la infantilización de las internas en un régimen tutelar dentro de la cárcel y la pérdida de contacto físico con la familia, principalmente los hijos.

Los hallazgos y conclusiones de este estudio son relativos al espacio donde se trabajó y al muestreo que se realizó, presentando algunas limitaciones que deben ser explicitadas para sugerir nuevas cuestiones que puedan ser utilizadas en otras investigaciones. No se tuvo acceso a la única interna que tenía un nivel socioeconómico más alto, pues se encontraba en labores de cocina como beneficio por su conducta; además, todas las entrevistas fueron realizadas al interior de la cárcel, por lo que resultaría interesante poder acceder al mundo del narcotráfico en los espacios de libertad como poblaciones, villas, ciudades, etc., pues es muy probable que algunas evaluaciones y valoraciones cambien al no tener la experiencia del encarcelamiento.

\section{Bibliografía}

Arriagada, Irma; Hopenhayn, Martín (2000):“Producción, tráfico y consumo de drogas en América Latina" en Serie Políticas sociales, No. 41, 3-49.

Baeza, Manuel (2002):De la metodología cualitativa en investigación científico-social. Diseño y uso de instrumentos en la producción de sentido. Primera Edición, Concepción: Universidad de Concepción.

Cánovas, Elena (2001):Quién le puso a mi vida tanta cárcel. Madrid:Dirección General de la Mujer. 
Cárdenas, Ana; Undurraga, Rosario (2014): "El sentido del trabajo en mujeres privadas de libertad en Chile" en Cuestiones de género: de la igualdad y la diferencia, No. 9, 286309.

Carrillo, Edith. (2012):“¿Vinculadas al narco? Mujeres presas por delitos contra la salud” enDesacatos, No. 34, 61-72.

Cooper, Doris. (2002):Criminología y delincuencia femenina en Chile. Santiago: Lom Ediciones.

Foucault, Michel (1975): Vigilar y Castigar. México: Editorial Siglo XXI.

Flick, Uwe (2007) Introducción a la metodología cualitativa. Madrid: Ediciones Morata.

Galindo, Luis; Catalán, Horacio. (2007): "Las actividades delictivas en el Distrito Federal" enRevista Mexicana de Sociología, vol. 69, No. 3, 457-484.

Gendarmería de Chile (2013): Compendio Estadístico Penitenciario 2013. Disponible en http://html.gendarmeria.gob.cl/doc/20141105 compendio estadistico/COMPENDIO E STADISTICO 2013.pdf

Goetz, J. y Le Compte, M. (1988):Etnografía y diseño cualitativo en investigación educativa. Conceptualización del proceso de investigación: teoría y diseño.Madrid: Ediciones Morata.

Héau, Catherine (2007): "El Narco-corrido como mini-relato de vida" enArena, revista Sinaloense de Ciencias Sociales, No. 12, 53-67.

Hopenhayn, Martín (2001):"Vida insular en la aldea global: paradojas en curso" enRevista Polis, Universidad Bolivariana, vol. 1, núm. 2.

Kalinsky, Beatriz (2003a):“Connotaciones diferenciales en la asunción del delito y formas específicas de la estadía carcelaria en hombres y mujeres” enNómades, núm. 10.

(2003b): "Las cárceles como objeto de estudio de la Antropología. Un estudio de Caso" enRevista Internacional de ciencias Sociales, UNESCO, núm. 178.

-------- (2004):"La metodología de investigación antropológica en ambientes criminógenos, Un estudio de caso"enGazeta de Antropología, No. 20, artículo 36.

Krippendorf, Klaus (1990): Metodología de análisis de contenido. Teoría y práctica. Barcelona: Ediciones Paidós.

Lander, Edgardo (2000):“¿Conocimiento para qué? ¿Conocimiento para quién? Reflexiones sobre la universidad y la geopolítica de los saberes hegemónicos" enRevista Venezolana de Economía y Ciencias Sociales, vol. 2, s/p.

Ordóñez, Laura. (2006): “Mujeres encarceladas: proceso de encarcelamiento en la penitenciaría femenina de Brasilia” enUniversitas Humanística, 183-199. 
Ovalle, Liliana; Giacomello, Corina. (2006):"La mujer en el "narcomundo". Construcciones tradicionales y alternativas del sujeto femenino" enLa ventana. Revista de estudios de género, no. 24, 297-318.

Rodríguez, Francisco; Paíno, Susana; Herrero, Francisco; González, Luis (1997): "Drogodependencia y delito. Una muestra penitenciaria" enPsicothema, 587598.

Ruiz Olabuénaga, José (2007). Metodología de investigación cualitativa. Bilbao: Universidad de Deusto.

Ruiz Olabuénaga, José e Ispizua, Maria (1989):La decodificación de la vida cotidiana. Bilbao: Universidad de Deusto.

Sandoval, Luis; Martínez, Deissy (2008): Una revisión al estudio de la delincuencia y criminalidad. Revista Facultad de Ciencias Económicas: Investigación y Reflexión, Vol. XVI [On line]. Disponible en: http://www.redalyc.org/articulo.oa?id=90916108

Silva de Sousa, Rosinaldo; Anaya, Isabel(2004):"Narcotráfico y economía ilícita: las redes del crimen organizado en Rio de Janeiro" enRevista Mexicana de Sociología, vol. 66, no. 1, 141-192.

Fecha de Recepción: 24-07-2014

Fecha de Aprobación: 14 de octubre 2015 